\title{
Mobile Marketing Strategies and Customer Patronage of Mobile Telecommunication Services
}

\author{
Obabuike Ikeni Nkpurukwe \\ Department of Business Administration \\ Federal University, Wukari, Nigeria \\ Emmanuel A. Amangala \\ Department of Marketing \\ Niger Delta University, Nigeria \\ Andy Fred Wali \\ Department of Business Administration \\ Federal University, Wukari, Nigeria
}

Received: July I5, 2020

Accepted: July 30, 2020

Online Published: August 17, 2020

doi: I0.4628I/ijmri.v4i2.7I4

URL: https://doi.org/I0.4628I/ijmri.v4i2.7I4

\begin{abstract}
This study empirically examines the relationship between mobile marketing strategies and customer patronage of mobile telecommunication services. The study applied a cross-sectional survey design in a structured questionnaire to collect data from 400 accessible telecom subscribers across the 4 major telecom operators which include; MTN, Glo, Aitel, and 9 Mobile. A total of 4 hypotheses were proposed and Spearman's Rank Correlation Coefficient tool was employed with the help of SPSS version 21.0, in statistically testing them. Findings revealed a positive and significant relationship between the dimensions of mobile marketing strategies and measures of customer patronage. The study, therefore, concludes that mobile marketing is an effective tool in improving purchase intention and referral. Therefore, the research recommends that telecom operators who want to improve patronage of subscribers should adopt mobile websites and SMS marketing; as these tools have been further verified to have a huge capacity to enhance purchase intention and customer referral.
\end{abstract}

Keywords: Mobile Marketing, SMS Marketing, Referral.

\section{Introduction}

It is almost impossible in this $2 \mathrm{I}^{\text {st }}$ century to go about day-to-day business activities without perceiving the importance of mobile devices in enhancing both individual and organization performance. Going hand-in-hand with this new mobile landscape where consumers and organizations have formed an eco-system of value co-creation; interaction, dialog, and collaboration drives the business system (Metric, 20I4). With respect to this paradigm shift (from traditional to mobile age), consumers have more than ever change their media preferences and habits from TV and radio broadcast to various sophisticated mobile devices powered by the internet. According to Akim (2010), today's generation consumers are expecting not only engaging and interactive ads, but more importantly an entertaining ad that is relevant to their personal needs. Time is fast-changing at the rate where users expectation and media consumption behaviour is moving from traditional media of the AIDA model; as awareness, to interest, to desire, and action has shifted to adoption of multiple touch screens with the advent of state-of-the art smart phones and tablets.

Therefore it is important for service organization in their bid to command customers' favourable purchase behaviour to recognize and understand this electronic transition so as to adopt appropriate mobile marketing strategies in reaching and serving multiple users. The ability to effectively reach real world user audience segments at the right time and place has become the holy grail of modern marketing, and mobile devices are the strategic channels used in driving this change (Zhang \& Li, 2012).Telecom service providers could leverage on the strategic lucrativeness of mobile marketing tools in improving subscriber satisfaction and patronage. More so, a combination of this crucial change in marketing with the usage or adoption level of smart phones, i-pads, tablets, and other internet connected mobile devices, it become pertinent that if telecom firms approach the mobile space the right way, they have an opportunity to develop the most effective advertising strategies that brings about the desired response from users (Kelli, 2009). To buttress this point further, a study conducted by Marketing Evolution (2012) 
reveals that GSM service providers have realize the role mobile devices play in achieving marketing goals. This has made them rethink holistically their integrated marketing communication towards mobile drivers and focus more on mobile web apps, search engine, and mobile viral marketing.

Stressing the importance of mobile Marketing tools, major telecom firms in Nigeria; which are MTN, Glo, Airtel, and 9 mobile have launched their various mobile application s as a way of effectively communicating their products and services to targeted audiences. This strategy affords the firms to engage and ensuring that subscribers have an exciting and memorable experience as they have the opportunity to conveniently pay for internet subscription their bank account, transfer airtime and mega-bites to family and friends, pay for other sundry services, and a lot more (Tahtinen, 20I0). Globacom for example, also launched a mobile-enhanced website and application where bulk SMS (short message services), can be used to disseminating information via content sharing apps such as display-base campaign and search engine marketing anywhere and anytime. These among other mobile marketing strategies are currently going on in the telecommunication industry in Nigeria.

Plethora of studies has investigated the effect of mobile marketing on several consumer purchase actions (Roach, 2009; Barnes \& Scornavacca, 2004; Carrol et al., 2007; Karjaluote et al., 2004). Despite the growing body of literature, there is still limited understanding as to the development of a more coherent model that conceptualizes these constructs. Most of the authors have focused more on consumer attitude and perception towards mobile marketing (Roach, 2009; Akin, 2010; Telli, 2009). These few scholars have used mobile applications, search engine marketing, display-base campaign, mobile video ads, as dimensions of mobile marketing in evaluating its effect on business outcomes (Shankara \& Balasubramanion, 2009; Tahtinen, 2005). However, this research deviated from extant literature by introducing mobile-compatible websites and Short Message Service (SMS) as dimensions of mobile marketing strategies in evaluating their effect on purchase intentions and referral as it relates to telecommunication firms in Rivers State.

Nigeria telecommunication industry is increasing witnessing stiff competition especially among the four major playersMTN, GLO, 9mobile, and Airtel. It may not be far from the truth to state that each one of these firms have expended considerable amount of resources in order to enhance subscriber patronage. While some may have experienced success in their marketing campaigns, however, the challenge of brand switching and low digital user-adoption is still prevalent. According to Nielsen Smartphone (2018), the GSM service providers market has witnessed low patronage occasioned by poor network services, un-accounted charges, unwarranted calls/SMS to subscribers, poor handling of subscribers' complaints and a host of other issues. This has led to reduced subscribers' loyalty and patronage.

In view of the above challenges, could mobile marketing strategies such as mobile-compatible website and SMS solve the issue of brand switching by improving subscribers' patronage in the GSM sub-sector? The answer to the above question forms the theoretical and empirical journey of this research.

In line with the aim of this research, the following hypotheses were examined:

Hor: Mobile-compatible website has no significant effect on purchase intention towards telecommunication services.

$\mathrm{H}_{02}$ : Mobile-compatible website has no significant effect on referral towards telecommunication services.

Ho3: SMS has no significant effect on purchase intention towards telecommunication services.

$\mathrm{H}_{04}$ : SMS has no significant effect on referral towards telecommunication services.

Below is the operational framework of the research:

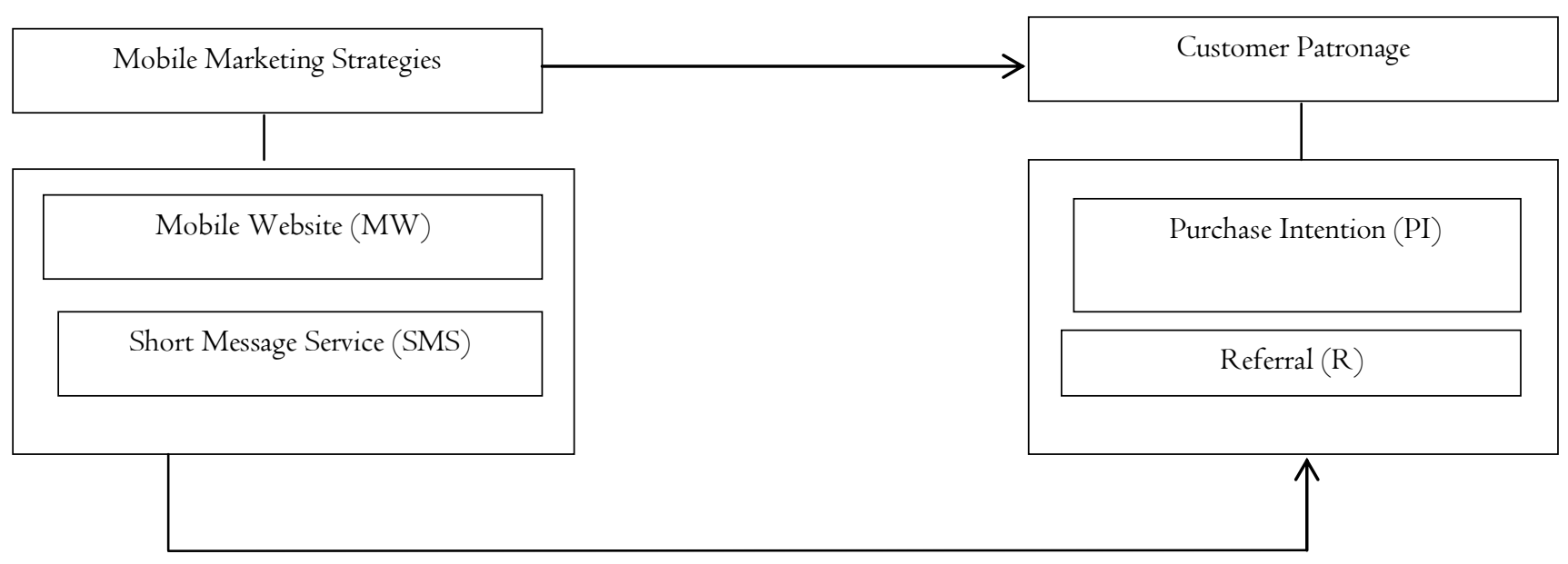

Figure I. Conceptual Framework of the Study

Source: Researchers' Conceptualization from review of related literature, 2020 


\section{Literature Review}

\section{Theoretical Foundation}

The theory upon which the present study is anchored is the Technology Adoption Model (TAM) propounded by Fred Davis in 1989. While this model has been widely used in technology adoption studies, its strength lies in the simplicity of its model. The TAM was developed drawing from the theory of reasoned action (TRA) by Ajzen. The TAM model was developed to determine user acceptance of a wide range of computing technologies (Davis, 1989). According to this author, two theoretical constructs were found useful in conceptualizing the TAM model. They are: perceived usefulness (PU) and Perceived Ease of use (PEOU). Both constructs according to this affects the intention to use a system. The author defined PU as the degree to which a person believes that using a particular system would enhance his or her job performance. More so, PEOU was defined as the degree to which a person believes that using a particular system would be free from effort. In relating this theory to the present study, underscores the importance of the use of mobile devices by consumers in their day-to-day activities. The rate of adoption of mobile devices may be determined by PU and PEOU. This however goes a long way to determining their intention to patronize a particular marketer. The adoption behaviour determines the degree to which consumers decides to use these mobile devices in their various activities. This is of primary concern to companies because if the adoption rate is not positive and favourable, then communicating product information and services to consumers via these systems (mobile media) may be hampered; hence, produces less result. It is however in view of this association, the researcher adopted the TAM as the theoretical foundation of this study.

\section{Concept of Mobile Marketing Strategies}

The concept of mobile marketing strategies has been examined by many scholars and several definitions have been put forward (Shankara \& Balasubramanan, 2009; Persound \& Azhar et al., 2005; Scharl et al., 2005). However, there is still no unified definition of mobile marketing among these authors. The Mobile Marketing Association (2008) defined mobile marketing as a set of practices which enable organization to communicate and collaborate with their public in an interactive and patent way through any mobile device or network. Scharl et al., (2005), defined the concept as consisting of the use of a wireless device to provide consumers, at the appropriate places and time, personalized information promoting goods, services, and ideas; thereby generating value for all stakeholders. In addition, Bauer et al (2000), sees mobile marketing as the use of mobile phones as a channel for the transmission of commercial contents to consumers.

Shankara \& Balasubramanian (2009), assert that mobile marketing is a medium through which markets reach target audience with their personal devices. Haglunian \& Madlberger (2005), noted that mobile advertising consisted of using interactive wireless media such as mobile phones, for transmission of personalized advertising messages to consumers, with the main aim of promoting their goods and services. An evaluation of the above definitions shows that mobile marketing is a means of effectively reaching target audiences with promotional messages, either personalized or not, directly to their mobile devices. Mobile marketing operates either by pushing promotional contents to target audiences or by pulling them to the sites where the needed content is available.

\section{Customer Patronage}

Patronage is something that customers may exhibit towards brands, services, stores, or product categories. A consistent patronage or re-purchase from a buyer demands that he/she is deeply committed to such firm or its product. Kotler and Keller (2006) points out that those customers who are brand loyalist do not evaluate the brand, they just make a purchase confidently based on their experiences. Customer patronage is the impulse, desire and consideration within customers which stimulate the purchase of goods and services from outlet. The relevance of a customer and its patronage per say is so profound that business firms cannot survive without. Studies conducted by Schiffman and Kanuk (2009); Kotler and Keller (2006) revealed that firm capacity, products or attributes, economic situation, political forces, social and psychological factors, situational competition, marketing mix program etc. are major influencers of customer patronage in a firm.

Olsen \& Connolly (2013), states that "patronage is usually measured by comparing customer's total week/monthly purchase (in money terms) from the store, with the normal family consumption in a month". Customer patronage is the approval or support provided by customers with respect to a particular brand. Patronage delivers the foundation for an established and growing market share. Kotler (2007) opines that customers have unpredictable degree of patronage to particular services, stores and other entities. In this study, customers can be categorized into four groups. These are; hard core patrons who are customers of one particular product always; split patrons, who usually become loyal to either two or three products within a specified period of time; shifting patrons, who move from one product to another and finally, switchers are customers who are not loyal to any brand at all (source). It is crucial to note that customer patronage in this study was measured using customer satisfaction and commitment. 


\section{Mobile Marketing Strategy and Customer Patronage}

An effective and integrated mobile marketing strategy uses a combination of the mobile tools, rather than only one to engage with customers. As such, marketers must be prepared to meet consumers where they are; study their usage patterns, and understand what makes them go from search to purchase (Jaokar \& Fish, 2006). Studies in the relationship between mobile marketing and customer patronage are enormous; however, major aspect of their findings suggests that mobile advertising has a strong correlation with brand awareness (Roach, 2009; Akin, 2010; Carrol et al., 2007; Teli, 2009). This however entails that companies can use mobile communication channels in shaping and directing consumer purchase behaviour.

\section{Mobile Website and Customer Patronage}

According to Christ (20II), mobile web is a version of desktop web that has been specifically designed to be compatible with mobile devices. MMA (2008), see mobile web as a software that deliver an engaging and streamlined mobile experience that appeals to a mobile visitor who is using their smart phone or other mobile devices to connect to a company's brand. This website affords mobile users the opportunity to connect through a markets network to the internet using inter-connect applications (Robins \& McCathie, 2008).Apart from becoming informed about products and services, customers want to partake in the service or product design process; they want a seamless access to innovations in the market (Camessa et al., 20I0). Since it is impossible to have stores located on every nook and cranny, Christ (20II), argued that service firms must provide customers with online access to almost everything they would find in the physical shop in order to create value for customers.

Scholars have explored the nexus between mobile web and customer patronage (Christ, 20I I) Canessa, et al (2010). Christ (20II) for instance, evaluated the impact of mobile webs on purchase behaviour. Result revealed that respondents whose age fall between 20 to 35 years use different website on their mobile device and tend to buy goods and services over the internet. The study further revealed that user attitude and awareness are influenced by mobile communication medium. Another study by Srinivasm et al., (2002), shows that about 500 million people accessed mobile internet across the world in 2009, and by 2014 the number moved up to about one billion. This however shows clearly that mobile web has a way of influencing customer patronage, because the growth in the usage of the system comes with knowledge about products and services of these firms. Bellman et al (20II), in their study mentioned that the usage rate of mobile devices in transacting business is increasing geometrically. They stated that service organization must see mobile web as a pipeline for seamless engagement with users and this engagement level brings about the desired response from users in terms of purchase intention and word-of-mouth referrals. Given the above, we hypothesized as follows:

Hor: Mobile website has no significant effect on purchase intention towards telecommunication services $\mathrm{H}_{02:}$ : Mobile website has no significant effect on referral towards telecommunication services

\section{Short Message Service (SMS) and Customer Patronage}

SMS has grown into a mainstream communication tool for marketers to reach millions of consumers. This platform provides firms with unprecedented opportunities to connect with customers by leveraging the massive rise in the use of mobile phones in the world (Criteo, 2015). As Harg et al., (2003) put it, whether the communication is between two people planning to transact business or a broadcast message to thousands of users, more and more customers have been converted via this medium, and alert marketers have realized that text messaging is a cost-effective way to communicate with their audience. The author stated that text messaging advertising is one of the known strategies used by non-profit organizations such as churches and government institutions.

By way of defining SMS tool by Vamali (2012), the concept may be viewed as a wireless service available on digital mobile networks. It enables the transmission of text messages between mobile phones and other electronic gadgets. The author further stated that among the mobile advertising applications, SMS is the most used method due to easy processing and low cost. The trend in research shows that SMS advertising is quickly surpassing e-mail technology as a tool for marketers in managing customer relationship (Siyarooshi et al., 2013; Islam, \& Salma, 20I4). SMS has now become an integral part of many firms media mix and it effective in reaching thousands of target audience (Kim \& Jim, 2008). A study by Kavassollis et al (2003) in Kenya suggest, that firms use SMS more than any other mobile marketing tool in communicating with their customers. The study further revealed that the independent Electoral and Boundaries Commission use SMS to pass voter registration calls, voter education and manage post-poll anxiety. According to Siyavooshi et al (2003) SMS marketing is the most widely used mobile communication. Moreover, SMS advertising is a tool that can effectively enhance customer patronage and repent buying (Eren, 2008). With SMS advertising marketers have the opportunity to engage users, which in turn shape their attitude and purchase intention (Vamali, 2012). We therefore hypothesized as follows:

$\mathrm{H}_{\text {o3: }}$ SMS has no significant effect on purchase intentions towards telecommunication services.

$\mathrm{H}_{\mathrm{o} 4:}$ SMS has no significant effect on referral towards telecommunication services. 


\section{Research Methods}

This research adopted quantitative approach of research design. The research specifically adopted the cross-sectional survey design in accessing its population of interest. The population of the study comprises of standard active subscribers of telecommunication services in Nigeria, but our accessible subscribers were those in Rivers State. More specifically, the study focused on active subscribers of services of four major telecommunication firms, namely; MTN, Globacom, 9Mobile, and Airtel. Users of these service providers constitute the study's population. The total GSM active voice subscribers in Rivers State is five million, eight hundred and forty nine thousand, five hundred and thirty five $(5,849,535)$ (NCC,2019).

However, the study purposively selected 400 respondents who are on their mobile phone contact log and this constituted the sample size as they were accessible to customers of GSM service providers and they were contacted by phone to submit their email addresses and copies of the questionnaire were forwarded to them. Personal contacts became a valid option because self-administration of questionnaires was affected by the outbreak of Covid-I9 in Nigeria with the attendant economic and social lockdown aimed at curbing its spread, hence the decision. The study adopted a combination of descriptive and inferential statistical tool in analyzing data. Hypotheses were tested using Spearman's Rank Correlation Coefficient. All analysis was done with the help of Statistical Package for Social Science (SPSS, 21.0 versions).

\section{Data Analysis and Discussion \\ Data Presentation}

Table I. Showing the Questionnaire Distribution Results

\begin{tabular}{lll}
\hline Questionnaire & Frequency & Percentage $\%$ \\
\hline Distributed & 400 & I00 \\
\hline Retrieved & 376 & 94 \\
\hline Not retrieved & 24 & 6 \\
\hline Retrieved usable & 347 & 92.3 \\
\hline Retrieved not usable & 29 & 7.7 \\
\hline & Source: Field Survey Data, 2020, SPSS 2I Output
\end{tabular}

400 copies of questionnaire were distributed as can be seen from table I, 376 were retrieved and 24 were not retrieved. Out of the 376 retrieved, 347 were usable, and 29 were not usable.

Table 2. Result of Test of Reliability

\begin{tabular}{ll}
\hline Variables & Cronbach's Alpha \\
\hline Mobile Website & 0.842 \\
\hline SMS Marketing & 0.801 \\
\hline Purchase Intention & 0.874 \\
\hline Referral & 0.899 \\
\hline
\end{tabular}

Source: Field Survey Data, 2020,SPSS 2I Output

The table above shows the results of the reliability test. As can be noticed, the Cronbach Alpha of all measures used in the instrument is above the threshold suggested in literature. Malhotra (2004) suggested a Cronbach alpha of 0.6 and above indicated satisfactory internal consistency. Hence, the research instrument is reliable.

\section{Test of hypotheses}

Hor: Mobile website has a positive and significant relationship with purchase intention towards telecommunication services

Table 3. Correlation Analysis showing the Relationship between Mobile Website and Purchase Intention

\begin{tabular}{|c|c|c|c|c|}
\hline \multicolumn{5}{|c|}{ Correlations } \\
\hline & & & Mobile Website & Purchase Intention \\
\hline \multirow[t]{6}{*}{ Spearman's rho } & \multirow[t]{3}{*}{ Mobile Website } & Correlation Coefficient & 1.000 & $.720^{\text {sht }}$ \\
\hline & & Sig. (2-tailed) & . & .000 \\
\hline & & $\mathrm{N}$ & 347 & 347 \\
\hline & \multirow[t]{3}{*}{ Purchase Intention } & Correlation Coefficient & $.720^{\text {sht }}$ & 1.000 \\
\hline & & Sig. (2-tailed) & .000 & . \\
\hline & & $\mathrm{N}$ & 347 & 347 \\
\hline
\end{tabular}

$$
\text { Source: Field Survey Data, 2020, SPSS 2I Output }
$$


From the table above, the correlation coefficient is 0.720 and it is significant $(p=0.000)$. This result indicates that there is a positive and significant relationship between mobile Website and purchase intention towards telecommunication services. Therefore, the hypothesis is accepted.

Hoz: Mobile website has a positive and significant relationship with referral towards telecommunication services

Table 4. Correlation Analysis Showing the Relationship between Mobile Website and Referral.

\begin{tabular}{|c|c|c|c|c|}
\hline \multicolumn{5}{|c|}{ Correlations } \\
\hline & & & Mobile Website & Referral \\
\hline \multirow[t]{6}{*}{ Spearman's rho } & \multirow[t]{3}{*}{ Mobile Website } & Correlation Coefficient & 1.000 & .813 \\
\hline & & Sig. (2-tailed) & . & .000 \\
\hline & & $\mathrm{N}$ & 347 & 347 \\
\hline & \multirow[t]{3}{*}{ Referral } & Correlation Coefficient & .813 & 1.000 \\
\hline & & Sig. (2-tailed) & .000 & . \\
\hline & & $\mathrm{N}$ & 347 & 473 \\
\hline
\end{tabular}

Correlation is significant at the 0.0I level (2-tailed).

Source: Field Survey Data, 2020, SPSS 2I Output

From the table above, the correlation coefficient is 0.813 and it is significant $(p=0.000)$. This result indicates that there is a positive and significant relationship between mobile website and referral towards telecommunication services. Therefore, the hypothesis is accepted.

Ho3: SMS has a positive and significant relationship with purchase intentions towards telecommunication services

Table 5. Correlation Analysis Showing the Relationship between SMS and Purchase Intention

\begin{tabular}{|c|c|c|c|c|}
\hline \multicolumn{5}{|c|}{ Correlations } \\
\hline & & & SMS & Purchase Intention \\
\hline \multirow[t]{4}{*}{ Spearman's rho } & \multirow[t]{2}{*}{ SMS } & Correlation Coefficient & 1.000 & .619 \\
\hline & & $\mathrm{N}$ & 347 & 347 \\
\hline & \multirow[t]{2}{*}{ Purchase Intention } & Correlation Coefficient & .619 & 1.000 \\
\hline & & Sig. (2-tailed) & .000 & . \\
\hline
\end{tabular}

Source: Field Survey Data, 2020, SPSS 2I Output

From the table above, the correlation coefficient is 0.619 and it is significant $(p=0.000)$. This result indicates that there is a positive and significant relationship between SMS and purchase intention towards telecommunication services. Therefore, the hypothesis is accepted.

Ho4: SMS has a positive and significant relationship with referral towards telecommunication services

Table 6.Correlation Analysis Showing the Relationship between of SMS and Referral.

\begin{tabular}{|c|c|c|c|c|}
\hline \multicolumn{5}{|c|}{ Correlations } \\
\hline & & & SMS & Referral \\
\hline \multirow[t]{6}{*}{ Spearman's rho } & SMS & Correlation Coefficient & 1.000 & .848 \\
\hline & & Sig. (2-tailed) & . & .000 \\
\hline & & $\mathrm{N}$ & 347 & 347 \\
\hline & Referral & Correlation Coefficient & .848 & 1.000 \\
\hline & & Sig. (2-tailed) & .000 & . \\
\hline & & $\mathrm{N}$ & 347 & 347 \\
\hline
\end{tabular}

Source: Field Survey Data, 2020, SPSS 2I Output 
From the table above, correlation coefficient is 0.848 and it is significant $(p=0.000)$. This result indicates that there is a positive and relationship between SMS and referral towards telecommunication services. Therefore, the hypothesis is accepted.

\section{Discussion of Findings}

From the preceding section, various hypotheses as proposed in the research were subjected to statistical tests. Results from these tests were discussed and compared with previous findings from related studies in this section. Findings from the test of $\mathrm{H}_{\mathrm{oI}}$ showed that a positive and significant relationship exists between mobile website and purchase intention $(\mathrm{R}=0.720)$. Also, Hoz test indicated mobile website has a strong and positive relationship with referral $(R=0.813)$.In summary, these results revealed that mobile website has a positive and significant relationship with customer patronage towards telecom firms in Rivers State. We therefore, reject the null hypothesis and accept that of the alternate. This is because the probability value is less than the stated level of confidence (PV<0.05). In view of the above findings Bellman et al (20I I) in their study mentioned that the usage rate of mobile devices in transacting business is increasing geometrically. They stated that service organization must see mobile web as a pipeline for seamless engagement with users and this engagement level brings about the desired response from users in terms of purchase intention and word-of-mouth referrals.

Furthermore, findings from $\mathrm{H}_{03}$ revealed that a positive and significant relationship exists between SMS and purchase intention $(\mathrm{R}=0.619)$. In addition to the result of $\mathrm{H}_{\mathrm{o}}$ test, it was discovered that SMS has a strong and positive relationship with referral $(\mathrm{R}=0.848)$. In summary, these results revealed that SMS has a positive and significant relationship with customer patronage towards telecom firms in Rivers State. We therefore, reject the null hypothesis and accept that of the alternate because the probability value is less than the stated level of confidence $(\mathrm{PV}<0.05)$. It is imperative to state that the above results corroborate with the study of Eren (2008) when the author found out that SMS marketing is a tool that effectively enhance customer patronage and repent buying. With SMS advertising marketers have the opportunity to engage users, which in turn shape their attitude and purchase intention. It is important to state that this research has contributed to extant knowledge as introduced variables into the pool of literature in the subject have expanded this discourse. Also, theoretically, this research has further validates the strong link between the criterion and predictor variables in relation to this subject.

\section{Conclusion and Managerial Implications}

The increasing importance of information \& technology has brought about a sharp rise in the usage of mobile devices in Rivers State, thereby opening strategic windows for service organizations particularly telecom service providers to better serve customers and build competitive advantages. Therefore, mobile marketing strategies are considered crucial marketing instrument for improving telecommunications service value. In other words mobile website and Short Message Service are valuable tools that could influence customer patronage positively. However, SMS revealed stronger effect on purchase intention and referral actions than mobile website. We recommend that telecom operators who expect to win customer patronage should use in addition to others; mobile website and SMS products, as these tools have been further validated to have strong influence on purchase intention and customer referral.

\section{References}

Akin, B. (20I0). Usage of current mobile marketing services and evaluation of potential future applications. Management information system, Quarterly, 2(I), 18-35.

Bauer, H. Reichardt, T. Barnes, S., \& Neumann, M. (2005). Driving consumer acceptance of mobile marketing: A theoretical framework and empirical study. Electronic commerce, 6(3), I8I-I92.

Carroll, A. Barius, Sccranaracca, E., \& Fletcer, K. (2007). Customer perception and attitude towards SMS advertising: Recent evidence from New Zealand. Internal Journal of Advertising, 26(3), 225-239.

Criteo, M. (2015), state of mobile commerce, USA.

Davis, F.A. (1989). Perceived usefulness, perceive ease of use and user acceptance of information technology. Marketing Information System Quarterly, 8, 3I8-339.

Eren, G. (2008). Advertising value of mobile marketing, activities, and consumer attitude. Istanbul, Institute of Science and Technology.

Haghirian, P. \& Madlberger, M. (2005). Consumer attitude towards advertising via mobile devices an empirical investigation among Austrian users. Proceedings of European Conference on Information Systems. Germany, I-I2.

Islam, K. A., \& Salma, U. (20I4). Customer satisfaction of Internet banking in Bangladesh: A case study on Citibank NA. Asian Journal of Applied Science and Engineering, 3(I), 5I-62. Retrieved from https://www.journals.abc.us.org/index.php/ajase/article/view/5I-62

Karjaluoto, H. Leppaniem, M., \& Salo, J. (2004). The role of mobile marketing in companies promotion mix: Empirical evidence from Finland. Journal of International Business and Economic, 2(I), I I I-I 24.

Kim, J. \& Kim, B. (200I). Korean consumers patronage of discount stores: Domestic versus multinational discount stored shoppers' profile. Journal of Consumer Marketing, I8(3), 236-255. 
Kohli, C. \& Leutheser, L. (20II). Brand equity: Capitalizing on intellectual capital. Journal of Marketing Management, 57, 3248.

Kotler, P and Keller, K. (2006), Marketing Management I2 ${ }^{\text {th }}$ Edition. New Jersey: Pearson Prentice Hall

Metric, K. (20I4). The marketing mix revisited: Towards the $2 \mathrm{I}^{\mathrm{st}}$ century marketing. Journal of Marketing Management, 22(3): 439-450.

Mobile Marketing Association (2008). Mobile marketing; a tool for business performance. Link address globalmarketing.com

Nielsen Smartphone (2018). Analysis of mobile adoption. Search Engine Marketing, USA.

Olsen, M.D. and Connolly, D.J. (2000). Experience-based travel, Cornell Hotel and Restaurant Administration Quarterly, 4I (I), 30-40.

Persavd, A. \& Azhar, I. (2012). Innovative mobile marketing via smartphones: Are consumers ready? Marketing intelligence and planning, 30: 418-443.

Roach, G. (2009). Consumer perception of mobile phone marketing: A direct marketing innovation. Internal Journal of Marketing, 3(2), I24-I38.

Shankara, Y., \& Balasabramanian S. (2009). Mobile marketing: A synthesis and prognosis. Journal of Interactive Marketing, 23, II8-I29.

Siyavooshi, M., Sanayei, A., \& Fathi, S. (2013). SMS advertising and consumer privacy: Analysis of factors affecting consumer willingness to send and received information in permission and Data base SMS advertising. New Marketing Research Journal, IOI-I24.

Tahtmen, J. (2005). Mobile advertising or mobile marketing. A Need for a New Concept Frontiers of Business Research in China, I52-164.

Telli, Y. G. (2009). Mobilized marketing and the consumer: Technological development and challenges. Istanbul: Business Science Reference, P. 292.

Zhang, R., \& Li, X. (2012). Research on consumer attitude and acceptance intentions towards mobile marketing. International Conference on Management Science and Engineering.

\section{Copyrights}

Copyright for this article is retained by the author(s), with first publication rights granted to the journal. This is an open-access article distributed under the terms and conditions of the Creative Commons Attribution license (http://creativecommons.org/licenses/by/4.0/). 